\title{
Serum Level of Intercellular Adhesion Molecule-1 in Children with Malignant Lymphoma
}

\author{
Nabil Abdelrazik ${ }^{a}$ Manal Fouda ${ }^{b}$ Mohammad Hosam El-deen Zaghloul ${ }^{c}$ \\ Dalia Abbas ${ }^{\text {d }}$ \\ aDepartment of Pediatrics, Pediatric Hematology, and Oncology, and Bone Marrow Transplantation Unit,

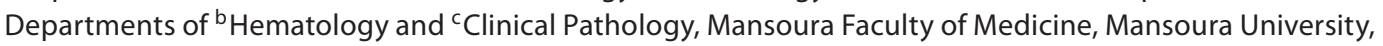 \\ and ${ }^{\mathrm{d} D e p a r t m e n t}$ of Clinical Pathology, Mansoura Health Insurance Hospital, Mansoura, Egypt
}

\section{Key Words \\ Lymphoma $\cdot$ Hodgkin's disease $\cdot$ Non-Hodgkin's \\ lymphoma $\cdot$ Intercellular adhesion molecule-1}

\begin{abstract}
Objective: To estimate the serum levels of soluble intercellular adhesion molecule-1 (s-ICAM-1) in children newly diagnosed with lymphoma and to correlate levels of s-ICAM-1 in lymphoma patients with clinical stage, pathological types, clinical and laboratory data and patient outcome. Subjects and Methods: Thirty-five children with newly-diagnosed malignant lymphoma (Non-Hodgkin's lymphoma, NHL: 23), Hodgkin's disease (HD: 12), and 8 apparently healthy subjects of matched age and sex taken as a control group were studied. For the patients and control group, the following tests were performed: complete blood count, and the following biochemical investigations: liver function tests, lactate dehydrogenase (LDH), and soluble ICAM-1 estimation using ELISA. In addition, for patients, pathological examination of lymph node biopsy for pathological grading, bone marrow aspiration and biopsy were done. Patients were observed for over 12 months or until death. Results: Serum ICAM-1 increased more in HD and NHL than in the control group ( $p<0.000)$; also s-ICAM-1 increased in advanced stag-
\end{abstract}

es and high-grade NHL ( $p<0.008,0.04$, respectively). LDH levels were higher in patients compared to controls $(p<$ 0.000 ). There was a positive correlation between high levels of s-ICAM- 1 and increased levels of LDH in HD $(r=0.72, p<$ 0.008 ) and a positive correlation between high levels of $s-$ ICAM-1 and increased ALT in NHL patients. A positive correlation between s-ICAM-1 levels and the presence of $B$ symptoms in $\mathrm{HD}$ and $\mathrm{NHL}$, and a positive correlation between elevated s-ICAM-1 levels and worse outcome in HD and NHL were detected. Conclusions: The data indicate that in children with malignant lymphoma, high serum levels of ICAM1 correlated with tumor aggressiveness, and quantification of s-ICAM-1 levels may identify a subgroup of children with worse prognosis. Therefore, detection of s-ICAM-1 levels in children with malignant lymphoma might represent an additional disease-associated marker for use in the clinical management of the patients. Copyright $\odot 2008$ S. Karger AG, Basel

\section{Introduction}

The term 'adhesion molecules' refers to those cell surface structures that allow cells to adhere to each other and the extracellular matrix. They are involved in every pro-

\section{KARGER \\ Fax +4161306 1234 \\ E-Mail karger@karger.ch}

www.karger.com
(C) 2008 S. Karger AG, Basel

$1011-7571 / 08 / 0173-0233 \$ 24.50 / 0$

Accessible online at:

www.karger.com/mpp
Dr. Nabil Abdelrazik

Consultant Pediatrics, Royal Commission Medical Center

P.O. Box 31100

Madinat Yanbu Al-Sinaiyah (Saudi Arabia)

Tel. +966 564853 716, Fax +9664392 8028, E-Mail nabeelabdelrazik2003@yahoo.com 
cess concerned with cell contact, such as antigen priming, recognition and activation of cells, as well as regulating leukocyte migration and localization within tissues during inflammation [1]. Intercellular adhesion molecule-1 (ICAM-1) is a membrane glycoprotein belonging to the immunoglobulin superfamily [2]. ICAM-1 has a role, among other physiologic pathways, in the immune response against tumor cells mediating the $\mathrm{T}$ cell cytotoxic response [3]. ICAM-1 (CD54) is found on the surface of vascular endothelial cells, fibroblasts, dendritic cells of the nervous system, leukocytes, monocytes and hematopoietic cells. After binding to the ligand CD11a/ CD18 (lymphocyte function antigen-1) and Mac-1 (CD11b/CD18) on the surface of T lymphocytes, it plays a role in their activation by enhancing the TCR/CD3 receptor signal [4-8]. Adhesion molecules are intimately involved in the control of morphologic differentiation, cellular proliferation, invasion and colonization of distant organs [9]. Elevated soluble ICAM-1 (s-ICAM-1) levels have been demonstrated in several malignant diseases and correlated with disease progression. The ICAM-1positive neoplastic cells release s-ICAM-1, suggesting that they may contribute to the high levels of s-ICAM-1 detected in cancer patients [10]. The last finding suggested that elevated levels of s-ICAM-1 represent an unfavorable prognostic marker in human neoplasias and that sICAM-1 can be used to monitor the course of the disease [11]. Concerning malignant lymphoma, it remains to be determined whether increased serum ICAM-1 levels simply reflect a greater tumor burden or this molecule contributes directly to the progression of the malignant process. The aim of this study was to estimate the serum levels of ICAM-1 in newly diagnosed children with malignant lymphoma (non-Hodgkin's lymphoma - NHL, and Hodgkin's disease - HD) and to study its correlation with the clinical stage, pathological types, clinical and laboratory data, and patient outcome.

\section{Subjects and Methods}

\section{Subjects}

This was a prospective randomized case-control study. Thirty-five children with newly diagnosed malignant lymphoma (NHL and HD) attending the Hematology/Oncology Unit of Mansoura University Children's Hospitals, Egypt, were studied. Eight age-matched healthy subjects were included as a control group ( 4 males and 4 females, ages ranging from 6 to 16, mean $10.1 \pm 2.2$ years). All patients began chemotherapy and were followed for over 12 months or until death. Both HD and NHL patients were diagnosed by histopathological examination of lymph node sections and classified according to Rye [12] and WHO [13], respectively. Clinical staging of $\mathrm{HD}$ and NHL were performed using the Ann Arbor classification [14]. The HD group included 12 patients ( 8 males, 4 females), ages ranging from 2.5 to 13 , mean $7.4 \pm 3.3$ years. They were further subclassified according to histologic subtypes as follows: mixed cellularity: 7, lymphocytic predominance: 3 , nodular sclerosis: 2 . The NHL group included 23 patients ( 16 males and 7 females), ranging in age from 2 to 17 , mean $8.5 \pm 4.5$ years. They were further subclassified according to the grade of lymphoma as follows: low-grade lymphoma: 5, high-grade lymphoma: 14, intermediate-grade lymphoma: 4. The patients with HD were treated with the COPP (cyclophosphamide, vincristine, procarbazine, prednisone) or the COPP-ABVD (adriamycin, bleomycin, vinblastine, dacarbazine) regimen. Patients with NHL were given COMMP (cyclophosphamide, methotrexate, vincristine, prednisone). Serum samples were obtained from all patients before treatment. Informed consent was obtained for all patients and controls, and the studies were approved by the hospital's Institutional Review Board.

\section{Methods}

A detailed history was obtained from controls and patients prior to treatment. Physical examination, complete blood count, and the following biochemical investigations: liver function tests, lactate dehydrogenase (LDH) enzyme, and assay of serum intercellular adhesion molecule-1 (ICAM-1) using the ELISA method were also done. All patients underwent a lymph node biopsy. Bone marrow aspiration and biopsy for all the cases to help in staging was performed for lymphoma patients.

\section{Specimen Collection and Storage}

A sample of $5 \mathrm{ml}$ of venous blood was collected under completely aseptic conditions from each subject (patients and controls): $1 \mathrm{ml}$ of blood was drawn in a tube containing EDTA for complete blood count; $4 \mathrm{ml}$ of blood was drawn into a plain tube and after clotting, serum was separated by centrifugation. The serum of each patient and control was divided into 2 Eppendorf pipettes to avoid multiple freeze-thaw cycles of frozen specimen. Eppendorf 1 was used fresh for LDH, ALT, AST, albumin and bilirubin. Eppendorf 2 was stored at $-20^{\circ} \mathrm{C}$ for serum ICAM- 1 assay.

\section{Assay of Serum ICAM-1 Using ELISA}

Serum ICAM-1 was determined using a kit obtained from BioSource International, Inc., Camarillo, Calif., USA. The sample or standard containing s-ICAM-1 $(200 \mu \mathrm{l})$ and a horseradish peroxidase (HRP)-conjugated monoclonal antibody to s-ICAM$1(50 \mu \mathrm{l})$ were pipetted into the wells of a microplate that had been precoated with a monoclonal antibody s-ICAM-1. Following incubation, unbound HRP-conjugated antibody was removed by washing and a solution of a substrate for HRP $(100 \mu \mathrm{l})$ was added to the wells. The reaction was stopped by an acid solution (stop solution, $100 \mu \mathrm{l}$ ) and the absorbance was measured at $450 \mathrm{~nm}$. The standard curve, prepared from five standard dilutions, was used for calculating the concentration of s-ICAM-1 in the samples.

Statistical Analysis

Data entry and analysis were performed using SPSS statistical package version 10 . The data were examined for normal distribu- 
Table 1. Comparison of s-ICAM-1 level (ng/ml) in the HD group according to stage and histopathology

\begin{tabular}{|c|c|c|c|c|c|}
\hline & \multicolumn{3}{|l|}{ Stage } & \multirow[t]{2}{*}{$\chi^{2}$} & \multirow[t]{2}{*}{$\mathrm{p}$} \\
\hline & $\mathrm{I}(\mathrm{n}=5)$ & II $(\mathrm{n}=4)$ & III $(\mathrm{n}=3)$ & & \\
\hline \multirow{4}{*}{$\begin{array}{l}\text { Median } \\
\text { Range }\end{array}$} & 1,210 & $1,578.5$ & $1,975.6$ & \multirow[t]{2}{*}{3.5} & \multirow[t]{2}{*}{0.16} \\
\hline & $860-1,609$ & $1,296.3-1,722$ & $1,053-1,987$ & & \\
\hline & \multicolumn{3}{|c|}{ Histopathology } & \multirow[t]{2}{*}{$\chi^{2}$} & \multirow[t]{2}{*}{$\mathrm{p}$} \\
\hline & NS $(n=2)$ & $\operatorname{LP}(n=3)$ & $\mathrm{MC}(\mathrm{n}=7)$ & & \\
\hline Median & 1,587 & $1,331.3$ & 1,286 & \multirow[t]{2}{*}{1.03} & \multirow[t]{2}{*}{0.59} \\
\hline Range & $1,570-1,722$ & $1,053-1,609.7$ & $860-1,987$ & & \\
\hline
\end{tabular}

Table 2. Comparison of s-ICAM-1 level (ng/ml) in the NHL group according to stage and histopathology

\begin{tabular}{|c|c|c|c|c|c|c|}
\hline & \multicolumn{4}{|l|}{ Stage } & \multirow[t]{2}{*}{$\chi^{2}$} & \multirow[t]{2}{*}{$\mathrm{p}$} \\
\hline & $\mathrm{I}(\mathrm{n}=14)$ & $\mathrm{II}(\mathrm{n}=3)$ & III $(\mathrm{n}=2)$ & $\mathrm{IV}(\mathrm{n}=4)$ & & \\
\hline \multirow{4}{*}{$\begin{array}{l}\text { Median } \\
\text { Range }\end{array}$} & 1,061 & 770 & 968 & $1,754.5$ & & \\
\hline & $400-1,380$ & $650-873$ & $933-1,003$ & $1,497-1,925$ & 11.9 & 0.008 \\
\hline & \multicolumn{4}{|c|}{ Histopathology } & \multirow[t]{2}{*}{$x^{2}$} & \multirow[t]{2}{*}{$\mathrm{p}$} \\
\hline & \multicolumn{2}{|l|}{$\begin{array}{l}\text { low grade } \\
(\mathrm{n}=5)\end{array}$} & $\begin{array}{l}\text { intermediate } \\
\text { grade }(n=4)\end{array}$ & $\begin{array}{l}\text { high grade } \\
(\mathrm{n}=14)\end{array}$ & & \\
\hline Median & \multirow{2}{*}{\multicolumn{2}{|c|}{$\begin{array}{l}873 \\
400-1,072\end{array}$}} & \multirow{2}{*}{$\begin{array}{l}930 \\
670-1,925\end{array}$} & $1,137.5$ & \multirow[b]{2}{*}{6.15} & \multirow[b]{2}{*}{0.04} \\
\hline Range & & & & $400-1,899$ & & \\
\hline
\end{tabular}

Stage IV versus stage I: $r=0.71, p=0.001$; stage IV versus stage II: $r=0.69, p=0.05$; high-grade versus lowgrade lymphoma: $\mathrm{r}=0.75, \mathrm{p}=0.01$.

tion using the Kolmogorov-Smirnov test. Mean and standard deviation were calculated for parametric data and the median for the nonparametric data. $\chi^{2}$ was used to find the association between row and column variables of qualitative data. Student $t$ test was used to compare means of two groups. The one-way ANOVA procedure produces a one-way analysis of variance for a quantitative dependent variable by a single factor (independent variable). The Mann-Whitney U test and Kruskal-Wallis $\mathrm{H}$ are nonparametric tests equivalent to the $t$ test and ANOVA, respectively. Correlation between variables was done using Pearson correlation for parametric data and Spearman rank correlation for nonparametric data. These tests detect whether or not the change in one variable was accompanied by a corresponding change in the other variable. For all of the above-mentioned statistical tests, the threshold of significance is fixed at $5 \%$ level ( $\mathrm{p}$ value). A p value of $>0.05$ indicates nonsignificant results; a $p$ value of $<0.05$ indicates a significant result, while a $\mathrm{p}$ value of $<0.001$ indicates a highly significant result.

ICAM-1 in Childhood Lymphoma

\section{Results}

All 35 patients studied had detectable serum ICAM-1 levels. The median level of s-ICAM-1 was $1,050 \mathrm{ng} / \mathrm{ml}$, ranging from 400 to $1,925 \mathrm{ng} / \mathrm{ml}$ in NHL patients, $1,433.1$ $\mathrm{ng} / \mathrm{ml}$, with a range from 860 to $1,987 \mathrm{ng} / \mathrm{ml}$ in $\mathrm{HD} ; 212.5$ $\mathrm{ng} / \mathrm{ml}$ ranging from 140 to $360 \mathrm{ng} / \mathrm{ml}$ for controls. The levels of s-ICAM-1 in both HD and NHL patients were therefore significantly higher than in controls $(\mathrm{p}=0.000)$. The difference between NHL and HD groups was statistically significant $(\mathrm{p}<0.01)$. In $\mathrm{HD}$, there was no statistically significant difference in s-ICAM-1 level among different stages $(\mathrm{p}=0.16)$ and among different pathological groups $(\mathrm{p}=0.59$; table 1$)$. Higher s-ICAM-1 levels were correlated with more advanced disease in NHL (stage IV vs. I, $\mathrm{p}=0.001$; stage IV vs. stage II, $\mathrm{r}=0.69, \mathrm{p}=0.05)$ and 
Table 3. Correlation between s-ICAM-1 level and clinical outcome in HD and NHL patients (mean $\pm \mathrm{SD}$ )

\begin{tabular}{lllll}
\hline & HD & Z & p \\
\cline { 2 - 3 } & non-survived $(\mathrm{n}=3)$ & survived $(\mathrm{n}=9)$ & & \\
\hline Serum ICAM-1 & $1,894.9 \pm 149.8$ & $1,272.9 \pm 275.5$ & -2.49 & 0.009 \\
\hline & $\mathrm{NHL}$ & $\mathrm{Z}$ & $\mathrm{p}$ \\
\cline { 2 - 3 } & non-survived $(\mathrm{n}=5)$ & survived $(\mathrm{n}=18)$ & & \\
\hline Serum ICAM-1 & $1,587.8 \pm 342.7$ & $938.91 \pm 283.7$ & -2.98 & 0.001 \\
\hline
\end{tabular}

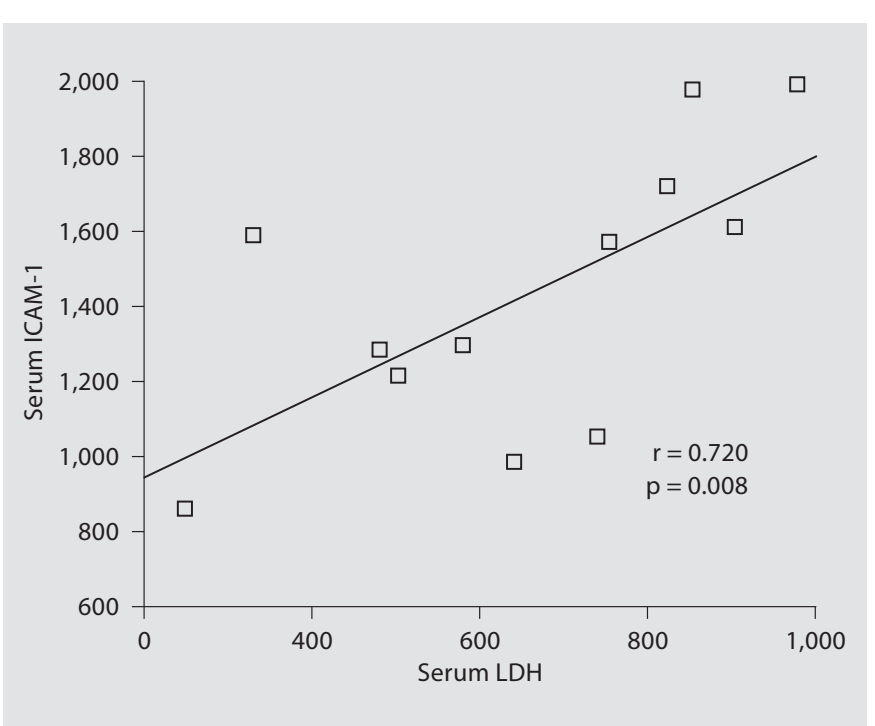

Fig. 1. Correlation between ICAM-1 and LDH levels in HD patients.

with high-grade compared to low-grade lymphoma $(\mathrm{r}=$ $0.75, \mathrm{p}=0.01$; table 2). In HD and NHL, higher levels of s-ICAM-1 were significantly correlated with the presence of constitutional (B) symptoms ( $\mathrm{p}=0.03,0.02$, respectively). Correlation between s-ICAM-1 and LDH levels in HD and NHL patients showed that there was a significant positive correlation between s-ICAM-1 and LDH levels in the HD group (fig. $1 ; \mathrm{r}=0.72, \mathrm{p}=0.008$ ), while there was no significant correlation between s-ICAM-1 and LDH levels in the NHL group $(\mathrm{r}=-0.27, \mathrm{p}=0.2)$. The relationship of serum ICAM-1 levels to treatment outcome in HD and NHL patients is illustrated in table 3. Bad outcome (death) was significantly more frequent among children with higher s-ICAM-1 levels at diagnosis in both $\mathrm{HD}$ and NHL patients (HD: $1,894.9 \pm 149.8 \mathrm{ng} / \mathrm{ml}, \mathrm{p}=0.009$; NHL: $1,587.8 \pm 342.7, \mathrm{p}=0.001)$. LDH was significantly higher in HD patients when compared to controls (HD: $652.3 \pm 228.6$, range: $251-976$; control: $168 \pm 64.7$, range: $59-256 \mathrm{IU} / \mathrm{l}, \mathrm{p}=0.00)$, and also in NHL patients (700 \pm 602.2 , range: $182-3,168 \mathrm{IU} / \mathrm{l}, \mathrm{p}=0.00)$. There was no significant correlation between s-ICAM-1 level and both the hematological and biochemical tests results either in HD or NHL patients.

\section{s-ICAM-1, Response to Treatment and Outcome}

A complete response (CR) to the primary therapy was achieved in 9 of $12 \mathrm{HD}$ (3 died of progressive disease) and 18 of 23 NHL patients (2 patients with resistant disease, 2 cases with relapse, and 1 with cardiomyopathy died during follow-up).

In the univariate analysis, there was a significant negative correlation between the levels of s-ICAM-1 and achievement of a CR, either as a continuous or dichotomized variable, $\mathrm{r}=-0.83, \mathrm{p}=0.0046$. Patients with low levels of s-ICAM-1 reached CR more frequently than those with high s-ICAM-1 [CR rates 10 (82\%) vs. $5(42 \%)$, respectively, $\mathrm{p}=0.023$ for $\mathrm{HD}$, and 17 (75\%) vs. 10 (45\%), $\mathrm{p}=0.002$, respectively, for NHL]. When a logistic regression for response achieved was performed, including LDH, B symptoms and s-ICAM-1 levels, only s-ICAM-1 as a continuous or dichotomized variable was predictive of response (relative risk - RR, 2.36, 95\% confidence interval - CI, 1.02-5.46; $\mathrm{p}=0.001)$.

\section{Discussion}

The highly significant s-ICAM-1 levels in both lymphoma groups in comparison to the control group and serum levels of ICAM-1 that are significantly higher in HD than in NHL of the present study are in agreement with previous reports [10,15-18]. Hatzistilianou et al. [15] and Tacyildiz et al. [16] have observed elevated serum levels of ICAM-1 in patients with childhood acute lympho- 
cytic leukemia and HD than those with acute myeloid leukemia, NHL, BL and normal children. Gomez-Scotto et al. [17] reported elevated serum levels of ICAM-1 in hematopoietic malignancies as lymphoma that may be attributed to ICAM-1 mediating lymphocyte adhesion directly so that it is highly expressed in lymphoma tumors. The elevated s-ICAM-1 levels during the advanced stage of HD, NS, and LP histologic subtypes compared to patients in earlier stages and MC histologic subtype of the present study are similar to those reported by Pui et al. [19]. Although the difference in s-ICAM-1 between advanced and early stages of HD was not statistically significant, it is not known whether increased serum ICAM1 levels result from shedding by normal host cells (because of the immune response to tumor, inflammation, or tissue damage) or by tumor cells. The higher levels in patients with more advanced malignancy may represent increased host immune response to malignant cells or may simply reflect a larger tumor burden. Hodgkin's Reed-Sternberg cells express ICAM-1, which could account for the higher serum levels observed in this malignancy. Hodgkin's Reed-Sternberg cells produce several cytokines, including interleukin-1, interferon gamma, and tumor necrosis factor. Thus, cytokine-induced expression of ICAM-1 by tumor or normal cells may be responsible for markedly increased serum levels in patients with advanced HD. Tacyildiz et al. [16] reported no statistically significant difference could be found when serum ICAM-1 titers were compared with stages, B symptoms, and histological subgroups. They suggest that at least part of serum ICAM-1 in childhood lymphoma patients probably originates from tumor cells. Cellular expression of ICAM-1 in HD tissues leads to release of sICAM- 1 and its accumulation in tissues and serum. This discrepancy of results might be due to the limited number of cases in each group in our study. In the present study, s-ICAM-1 was significantly elevated in advanced stages of NHL patients. Stage IV presented significantly higher values when compared to stages I and II. This is in agreement with the elevated s-ICAM-1 levels that have been demonstrated in late stages III and IV in a study made by Christiansen et al. [20]. They suggested that a possible source for s-ICAM-1 in NHL could be malignant cells through a proteolytic cleavage, so the later the stage of the disease, the bigger the number of involved lymph nodes, hence the higher the level of s-ICAM-1. Serum ICAM-1 was significantly higher also in high-grade NHL than low-grade tumors in agreement with the study of Maio et al. [21]. The functional role of cellular and soluble ICAM-1 in patients with malignancy is unclear. The in- teraction of ICAM-1 and leukocyte function-associated antigen 1 is crucial in nonmajor histocompatibility complex-restricted cell interactions. Hence, cellular expression of ICAM-1 by tumor cells may initially enhance immune recognition and thereby facilitate tumor cytolysis. If the tumor cells survive this phase of immunosurveillance, active growth may lead to shedding of soluble ICAM-1 [19]. The current study revealed a significantly higher LHD level in patients when compared to controls. Like the present results, serum LHD levels were reported to be one of the most important prognostic parameters together with age, stage and pathological classification in a study done by Raemaekers et al. [22]. We also found that there is a significant positive correlation between the levels of s-ICAM-1 and that of LDH in HD. This is in agreement with Christiansen et al. [23], who demonstrated that a high level of s-ICAM-1 correlates with adverse prognostic factors in HD, and Terol et al. [24], who found a positive correlation between high levels of s-ICAM-1 and increased levels of LDH in HD. The correlation between the different hematological, serum biochemical tests and serum ICAM-1 level in the HD and NHL groups revealed no significant correlation between the hematological parameters in the lymphoma groups and the elevated serum ICAM-1. Moreover, there is a slight elevation in ALT in cases with elevated s-ICAM-1 in NHL. This may be due to liver infiltration, which is common in NHL. The changes in liver function tests and the elevated s-ICAM-1 noticed in NHL are in agreement with that reported by Hudson and Donald [25], who noticed that NHL creates a leukemia-like picture by spreading over into the blood, resulting in early metastasis in organs such as the liver, which in turn causes a change in liver enzymes. There was a significant positive correlation between the s-ICAM-1 level and the presence of B symptoms in HD and NHL. This is in agreement with the studies by Christiansen et al. [23] and Terol et al. [24]. They found a significant correlation between high levels of sICAM-1 and the presence of B symptoms, advanced stage, and increased levels of LDH. Syrigos et al. [18] revealed a strong positive association of B symptoms with higher serum levels of ICAM-1, indicating that s-ICAM-1 may contribute to the development of these symptoms, possibly through interaction with the cytokines IL-1 and CD25. The highly significant correlation between a high s-ICAM-1 level and lower survival in patients with NHL and HD in our study is in agreement with that reported by Pui et al. [19]. They stated that higher serum levels of ICAM-1 were associated with advanced disease and a poorer treatment outcome in HD. A positive correlation 
has been described by de Paoli et al. [26]. Other investigators $[15,16,24]$ have also reported a positive correlation between high serum levels of ICAM-1 and adverse clinical outcome of patients with NHL. In contrast to our study, Tacyildiz et al. [16] found that in patients with NHL, sICAM-1 level was not significantly associated with survival.

\section{Conclusion}

Our data show that a high pretreatment serum s-ICAM-1 level was associated with poor response to treatment and poor survival in children with HD and NHL. Therefore, detection of serum s-ICAM-1 levels in patients with HD and NHL might represent an additional disease-associated marker for use in the clinical management of individual patients.

\section{References}

1 Sancho D, Yanez-Mo M, Tejedor R, SanchezMadrid F: Activation of peripheral blood T cells by interaction and migration through endothelium: role of lymphocyte function antigen-1/intercellular adhesion molecule-1 and interleukin-15. Blood 1999;93:886-896.

-2 Robledo O, Papaioannou A, Ochietti B, Beauchemin C, Legault D, Cantin A, King PD, Daniel C, Alakhov VY, Potworowski EF, St-Pierre Y: ICAM-1 isoforms: specific activity and sensitivity to cleavage by leukocyte elastase and cathepsin G. Eur J Immunol 2003;33:1351-1360.

3 Janeway C, Travers P, Walport M, Capra J: The development of mature lymphocytes receptor repertories: signaling through immune system receptors; in Janeway C, Travers $P$, Walport M, Shlomchik M (eds): Immunobiology: the Immune System in Health and Disease, ed 2. Edinburgh, Churchill Livingstone, 2001, p 213.

-4 Arkin S, Naprstek B, Guarini L, Ferrone S, Lipton JM: Expression of intercellular adhesion molecule-1 (CD54) on hematopoietic progenitors. Blood 1991;77:948-953.

5 Klickstein LB, Springer TA: CD54 (ICAM-1) Cluster Report. Leucocyte Typing V. Oxford, Oxford University Press, 1995, vol 2, pp 1548-1550.

6 Smith MEF, Thomas JA: Cellular expression of lymphocyte function associated antigens and the intercellular adhesion molecule- 1 in normal tissue. J Clin Pathol 1990;43:893900.

7 Spring TA: Adhesion receptors of the immune system. Nature 1990;346:425-434.

8 Wawryk SO, Novotny JR, Wicks IP, Wilkinson D, Maher D, Salvaris E, Welch K, Fecondo J, Boyd AW: The role of the LFA-1/ICAM1 interaction in human leukocyte homing and adhesion. Immunol Rev 1989;108:135161.

9 Albelda SM: Role of integrins and other cell adhesion molecules in tumor progression and metastasis. Lab Invest 1993;68:4-17.
10 Tsujisaki M, Imai K, Hirata H, Hanzawa Y, Masuya J, Nakano T, Sugiyama T, Matsui M, Hinoda Y, Yachi A: Detection of circulating intercellular adhesion molecule-1 antigen in malignant diseases. Clin Exp Immunol 1991; 85:3-8.

11 Lei KI, Johnson PJ: The prognostic significance of serum levels of soluble intercellular adhesion molecule-1 in patients with primary extranodal non-Hodgkin's lymphoma. Cancer 2000;89:1387-1395.

12 Lukes RJ, Butler JJ: The pathology and nomenclature of Hodgkin's disease. Cancer Res 1966;26:1063-1083.

13 Berard C, O'Conor GT, Thomas LB, Torloni H: Histopathological definition of Burkitt's tumor. Bull World Health Organ 1969;40: 601-607.

14 Carbone PP, Kaplan HS, Musshoff K, Smithers DW, Tubiana M: Report of the Committee on Hodgkin's Disease Staging Classification. Cancer Res 1971;31:1860-1861.

15 Hatzistilianou M, Athanassiadou F, Agguridaki C, Catriu D: Circulating soluble adhesion molecule levels in children with acute lymphoblastic leukaemia. Eur J Pediatr 1997; 156:537-540.

16 Tacyildiz N, Yavuz G, Gozdasoglu S, Unal E, Ertem U, Duru F, Ikinciogullari A, Babacan E, Ensari A, Okcuoglu-Cavdar A: Serum levels and differential expression of intercellular adhesion molecule-1 in childhood leukemia and malignant lymphoma: prognostic importance and relationship with survival. Pediatr Hematol Oncol 1999;6:149-158.

-17 Gomez-Scotto E, Seigneur M, Renard M, Houbouyan-Reveillard LL, Boisseau MR: Interest in variations in soluble ICAM-1 plasma levels. From physiology to clinical applications. J Mal Vasc 2000;25:156-165.

-18 Syrigos KN, Salgami E, Karayiannakis AJ, Katirtzoglou N, Sekara E, Roussou P: Prognostic significance of soluble adhesion molecules in Hodgkin's disease. Anticancer Res 2004;24:1243-1247.
19 Pui CH, Luo X, Evans W, Martin S, Rugg A, Wilimas J, Crist WM, Hudson M: Serum intercellular adhesion molecule-1 in childhood malignancy. Blood 1993;82:895-898.

20 Christiansen I, Gidlof C, Wallgren AC, Simonsson B, Totterman TH: Serum levels of soluble intercellular adhesion molecule 1 are increased in chronic B-lymphocytic leukemia and correlate with clinical stage and prognostic markers. Blood 1994;84:30103016.

21 Maio M, Pinto A, Carbone A, Zagonel V, Gloghini A, Marotta G, Cirillo D, Colombatti A, Ferrara F, Del Vecchio L, Ferrone S: Differential expression of CD54/intercellular adhesion molecule-1 in myeloid leukemias and in lymphoproliferative disorders. Blood 1990;76:783-790.

22 Raemaekers JM, Snoeijen JJ, Bogman MJ, Rutten E, Strijk SP, Manni JJ: Prognostic significance of the histological classification and staging for patients with a malignant non-Hodgkin lymphoma (in Dutch). Ned Tijdschr Geneeskd 1993;137:815-820.

23 Christiansen I, Enblad G, Kalkner KM, Gidlof C, Glimelius B, Totterman TH: Soluble ICAM-1 in Hodgkin's disease: a promising independent predictive marker for survival. Leuk Lymphoma 1995;19:243-251.

- 24 Terol MJ, Tormo M, Martinez-Climent JA, Marugan I, Benet I, Ferrandez A, Teruel A, Ferrer R, Garcia-Conde J: Soluble intercellular adhesion molecule-1 (s-ICAM-1/sCD54) in diffuse large B-cell lymphoma: association with clinical characteristics and outcome. Ann Oncol 2003;14:467-474.

25 Hudson M, Donald S: Principles and Practice of Pediatric Oncology. Philadelphia, Lippincott Williams and Wilkins, 2000, p 643.

-26 de Paoli P, D’Andrea M, Santini G, Zagonel V, Pinto A, Carbone A: Serum levels of adhesion molecules in haematopoietic tumours. Immunol Today 1994;15:339. 